\title{
Serum cytokine profile in the subclinical form of visceral leishmaniasis
}

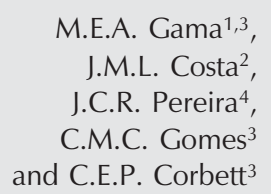

\author{
Departamentos de ${ }^{1}$ Pediatria and ${ }^{2}$ Patologia, Universidade Federal do Maranhão, \\ São Luís, MA, Brasil \\ ${ }^{3}$ Departamento de Patologia, Faculdade de Medicina, Universidade de São Paulo, \\ São Paulo, SP, Brasil \\ ${ }^{4}$ Laboratório de Epidemiologia e Estatística, Instituto Dante Pazzanese, \\ São Paulo, SP, Brasil
}

\section{Correspondence \\ M.E.A. Gama \\ Departamento de Patologia \\ Faculdade de Medicina, USP \\ Av. Dr. Arnaldo, 455 \\ 1ำ andar, Sala 1215 \\ 01246-902 São Paulo, SP \\ Brasil \\ Fax: +55-11-3081-7799 \\ E-mail: ruyflexa@elo.com.br or \\ monica.polo@ufma.br \\ Presented at the I Symposium on Advances in Medical Research, Institute of Medical Investigation Laboratories, HC-FMUSP, São Paulo, SP, Brazil, March 21-22, 2003. \\ Research supported by FAPESP, CNPq and the Laboratório de Patologia de \\ Doenças Infecciosas, Universidade de São Paulo (LIM50)}

Received June 12, 2003 Accepted August 12, 2003 $\ldots \ldots \ldots \ldots \ldots \ldots \ldots$

\begin{abstract}
The factors determining the development or not of visceral leishmaniasis (VL) have not been completely identified, but a Leishmaniaspecific cellular immune response seems to play a fundamental role in the final control of infection. Few studies are available regarding the production of cytokines in the subclinical form of VL, with only the production of IFN- $\gamma$ and TNF- $\alpha$ known. The aim of the present study was to identify immunological markers for the oligosymptomatic or subclinical form of VL. A prospective cohort study was conducted on 784 children aged 0 to 5 years from an endemic area in the State of Maranhão, Brazil, between January 1998 and December 2001. During 30 consecutive months of follow-up, 33 children developed the oligosymptomatic form of the disease and 12 the acute form. During the clinical manifestations, serum cytokine levels were determined in 27 oligosymptomatic children and in nine patients with the acute form using a quantitative sandwich enzyme immunoassay. In the subclinical form of VL, variable levels of IL-2 were detected in $52.3 \%$ of the children, IL-12 in $85.2 \%$, IFN- $\gamma$ in $48.1 \%$, IL-10 in $88.9 \%$, and TNF$\alpha$ in $100.0 \%$, with the last two cytokines showing significantly lower levels than in the acute form. IL-4 was not detected in oligosymptomatic individuals. Multiple discriminant analysis used to determine the profile or combination of cytokines predominating in the subclinical form revealed both a Leishmania resistance (Th1) and susceptibility (Th2) profile. The detection of both Th1 and Th2 cytokine profiles explains the self-limited evolution accompanied by the discrete alterations observed for the subclinical form of VL.
\end{abstract}

\section{Introduction}

Visceral leishmaniasis (VL) or kala-azar represents a serious public health problem in developing countries such as Brazil (1). Clinically, VL can present as infection (asymptomatic form), with few symptoms (oligosymptomatic or subclinical form), or with exuberant manifestations (classic or acute form) (2).
Key words

- Visceral leishmaniasis

- Cytokine levels

- Immunological aspects

- Subclinical form

- Oligosymptomatic form 
important role in the outcome of the infection $(3,4)$.

With Leishmania being recognized as an obligate intracellular parasite of macrophages, studies have demonstrated that the specific immunity in VL is mediated by CD4+ T helper (Th) cells and that disease susceptibility is associated with the inability to produce a macrophage-stimulating cytokine profile (Th1 profile) including interferon-gamma (IFN- $\gamma$ ) and interleukins (IL)-2 and-12, while, on the other hand, an elevated production of immunosuppressive cytokines such as IL-10 and IL-4 (Th2 profile), as well as high levels of tumor necrosis factor-alpha (TNF- $\alpha$ ), is observed (5-11).

Few studies are available in the literature regarding the production of cytokines in subclinical cases of $\mathrm{VL}$, and these investigations only determined IFN- $\gamma$ and TNF- $\alpha$ levels before the occurrence of clinical manifestations $(6,7,12)$. Carvalho et al. (12) observed high levels of IFN- $\gamma$ in oligosymptomatic individuals who evolved to spontaneous cure, supporting the fact that resistance is related to an efficient cellular immune response.

A great challenge faced in daily clinical practice is the fact that no predictive factor exists for the oligosymptomatic form whose clinical manifestations are discrete and nonspecific. Gama (13) has shown that a combination of fever, hepatomegaly, hyperglobulinemia and increased erythrocyte sedimentation rate in individuals with Leishmaniapositive serology can predict the subclinical form of VL, as long as these symptoms are not associated with splenomegaly or leukopenia. Therefore, the objective of the present study was to determine the serum cytokine levels directly or indirectly involved in the immune response of individuals with the oligosymptomatic form of VL who present clinical manifestations in order to establish a correlation between the clinical-evolutive behavior of the disease and cytokine production.

\section{Material and Methods}

\section{Study population}

The study population consisted of individuals who participated in a prospective cohort study carried out in the State of Maranhão, Brazil, during the period from January 1998 to December 2001 (13). In this cohort, 784 children were followed up monthly for four consecutive years in order to determine the behavior of the clinical forms of VL in general and to define the clinical-laboratory profile of the oligosymptomatic or subclinical form of VL in particular. The children were recruited from the 0 - to 5-year population of two localities in the municipality of Raposa, Maranhão (Vila Nova and Vila Bom Viver) which are endemic for VL, with a $28 \%$ incidence of infection and a $28: 1$ infection/disease ratio in children aged up to 5 years (14).

During follow-up, 33 children developed the oligosymptomatic form of VL and 12 the acute form. However, due to initial operational difficulties, material was collected and analyzed from only 27 oligosymptomatic cases and nine with the acute form. In the study of Gama (13), the subclinical cases evolved to spontaneous cure within a mean period of 15 days without evolution to the acute form of VL.

The study was approved by the Ethics Committees of the University of São Paulo and the Federal University of Maranhão according to Resolution 196/96 of the National Health Council for research involving humans. Written informed consent was obtained from parents or persons responsible for the children.

\section{Determination of cytokines}

During the symptomatic period, venous blood samples $(5-10 \mathrm{ml})$ were collected from the individuals and stored in the refrigerator until centrifugation (1000 rpm for $5 \mathrm{~min}$ in a 
cooled centrifuge) on the same day. Serum was separated, aliquoted and stored at $-70^{\circ} \mathrm{C}$ until the time of the tests. Serum IFN- $\gamma$, TNF- $\alpha$, IL-2, IL-4, IL-10 and IL-12 levels were determined by ELISA using a quantitative sandwich enzyme immunoassay technique (Quantikine ${ }^{\circledR}$ Kits, R\&D Systems, Minneapolis, MN, USA).

All tests were carried out by rigorously following manufacturer instructions. Serum cytokine levels were calculated by interpolating the standard curve for absorbance readings of test samples calculated from samples of known concentrations supplied with the kits and assayed in parallel. The sensitivity of the tests was $8 \mathrm{pg} / \mathrm{ml}$ for IFN- $\gamma, 4.4 \mathrm{pg} / \mathrm{ml}$ for TNF- $\alpha, 4.8 \mathrm{pg} / \mathrm{ml}$ for IL-2, $5 \mathrm{pg} / \mathrm{ml}$ for IL-4, $3.9 \mathrm{pg} / \mathrm{ml}$ for IL- 10 , and $5.0 \mathrm{pg} / \mathrm{ml}$ for IL- 12 .

\section{Statistical analysis}

The data were processed using the SPSSPC statistical program (Statistical Package for Social Sciences, PC version 10.0). Initially, mean cytokine levels were compared between groups using the Student $t$-test and the Mann-Whitney test and, when applicable, the $95 \%$ confidence intervals were calculated for descriptive analysis of the data. The level of significance was set at $\mathrm{P} \leq 0.05$.

Uni- and multivariate analyses were used to determine possible immunological markers of the oligosymptomatic form. However, since the production of a cytokine cannot be considered separately and due to the small number of individuals in each group and the variability in the different cytokine levels, multiple discriminant analysis (MDA) was used to estimate a value for all cytokines, thus establishing a profile or a combination of cytokines that could discriminate between the subclinical or oligosymptomatic form of VL.

\section{Results}

Table 1 shows the minimum and maximum serum cytokine levels during the symp- tomatic period for 27 subclinical or oligosymptomatic cases and for nine cases with the acute form of VL. IFN- $\gamma$ was detected in $48.1 \%$ of oligosymptomatic children, IL-2 in $52.3 \%$ and IL-12 in $85.2 \%$, but these cytokines were not detected in patients with the acute form. IL-4 was detected in 100\% of cases of acute disease but not in the subclinical form group. IL-10 was identified in $88.9 \%$ of oligosymptomatic children and in $100 \%$ of patients with the acute form of VL. TNF$\alpha$ was present in $100 \%$ of the individuals of both groups.

Comparative analysis of the two groups revealed significantly higher mean IL-10 and TNF- $\alpha$ levels for the acute form (IL-10, P =

Table 1. Serum cytokine levels of 27 oligosymptomatic individuals and 9 children with the acute form of visceral leishmaniasis and prevalence of detection for each cytokine.

\begin{tabular}{|c|c|c|c|c|c|}
\hline \multirow[t]{2}{*}{ Cytokine } & \multirow[t]{2}{*}{ Clinical form } & \multicolumn{3}{|c|}{ Serum level (pg/ml) } & \multirow{2}{*}{$\begin{array}{c}\text { Prevalence of } \\
\text { cytokine } \\
\text { detection (\%) }\end{array}$} \\
\hline & & Minimum & Maximum & Mean & \\
\hline IL-2 & Oligosymptomatic & 0 & 130.5 & 9.2 & 52.3 \\
\hline IL-4 & Acute form & 6.5 & 253.0 & 148.6 & 100 \\
\hline \multirow[t]{2}{*}{ IL-10 } & Acute form & 7.4 & 227.9 & 107.0 & 100 \\
\hline & Oligosymptomatic & 0 & 100.7 & 28.3 & 88.9 \\
\hline IL-12 & Oligosymptomatic & 0 & 116.0 & 31.6 & 85.2 \\
\hline IFN- $\gamma$ & Oligosymptomatic & 0 & 173.3 & 28.2 & 48.1 \\
\hline \multirow[t]{2}{*}{ TNF- $\alpha$} & Acute form & 12.4 & 226.3 & 89.0 & 100 \\
\hline & Oligosymptomatic & 1.3 & 58.0 & 19.8 & 100 \\
\hline
\end{tabular}

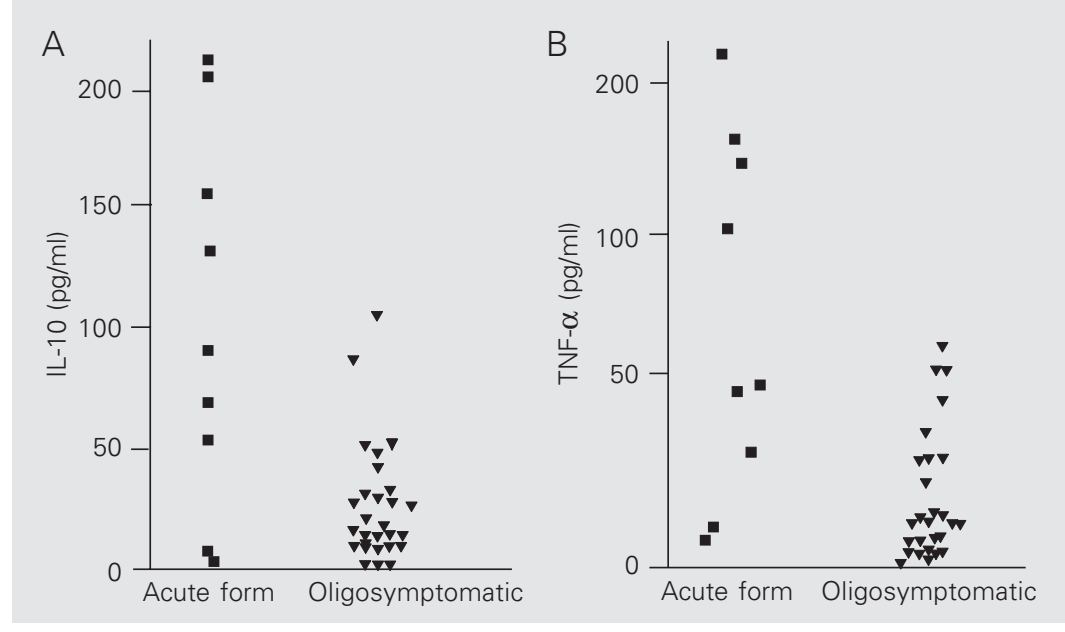

Figure 1. Serum IL-10 (A) and TNF- $\alpha$ (B) levels in 27 children classified as oligosymptomatic and in 9 children with the acute form of visceral leishmaniasis. 
0.003 and TNF- $\alpha, \mathrm{P}=0.005$ ). Figure 1 (A and $\mathrm{B})$ illustrates the variation in the levels of these cytokines observed for the two groups.

Based on the assumption that a specific cytokine profile (Th2) is produced in the acute form of VL, MDA was carried out to determine the cytokine profile or combination distinguishing the subclinical form. The importance of each variable for the discriminant model was defined by its correlation coefficient with each function, as shown in Table 2. Two different combinations of vari-

Table 2. Multiple discriminant analysis. Correlation between variables and discriminant functions.

\begin{tabular}{lccc}
\hline & \multicolumn{3}{c}{ Function } \\
\cline { 2 - 4 } & 1 & 2 & 3 \\
\hline TNF- $\alpha$ & $\mathbf{0 . 9 2 9}$ & -0.049 & -0.070 \\
IL-10 & $\mathbf{0 . 8 9 5}$ & -0.129 & 0.070 \\
IL-4 & $\mathbf{0 . 6 7 0}$ & -0.244 & -0.370 \\
IL-2 & -0.117 & $\mathbf{0 . 8 4 8}$ & -0.239 \\
IL-12 & -0.145 & $\mathbf{0 . 8 2 1}$ & 0.292 \\
IFN- $\gamma$ & -0.075 & -0.013 & $\mathbf{0 . 9 3 2}$ \\
\hline
\end{tabular}

Variables are given in order of the correlation coefficient obtained for each function. The major correlation coefficient obtained for each function is given in bold.

Figure 2. Mean and $95 \%$ confidence intervals $(95 \% \mathrm{Cl})$ for the cytokine combinations (discriminant functions obtained by multiple discriminant analysis) that characterize the Th1 and Th2 profiles obtained for each group.

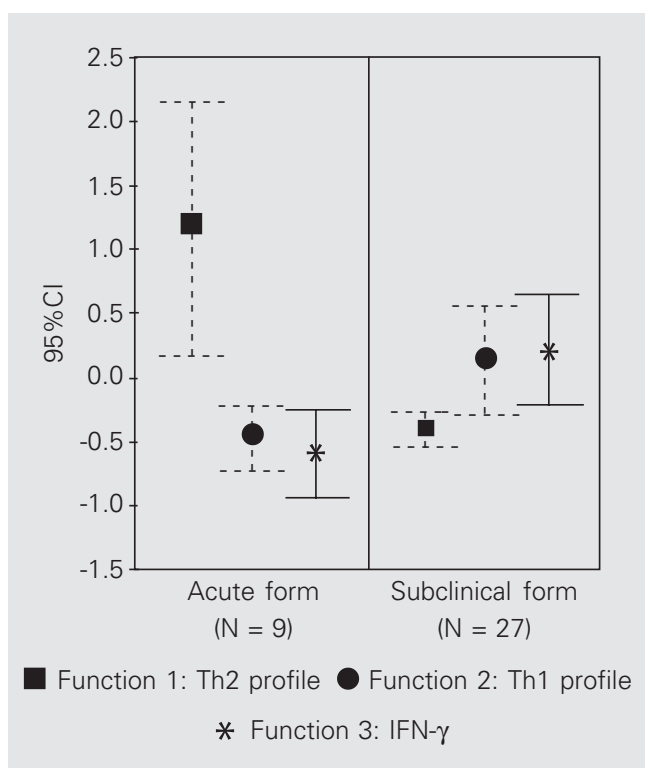

ables were found to distinguish between the subclinical and acute forms (combination or discriminant function 1 = detection of IL-4, IL-10 and TNF- $\alpha$; combination $2=$ IL- 2 and IL-12). These two discriminant functions obtained by MDA corresponded to about $80 \%$ of the variations observed. The detection of IFN- $\gamma$ (third function) complemented the discrimination of the clinical forms.

MDA showed that the combination of IL-4, IL-10 and TNF- $\alpha$ characterized function 1 as a Th 2 cytokine profile and function 2 , the combination of IL-2 and IL-12, as a Th1 profile, with IFN- $\gamma$ forming a third function which complemented the Th1 profile. Figure 2 shows the means and respective confidence intervals for the variables (cytokine profile) obtained for each group. Significant differences in the functions obtained were observed between the two groups (function $1, \mathrm{P}=0.006$; function $2, \mathrm{P}=0.013$, and function $3, \mathrm{P}=0.004$ ).

Figure 3A-C shows the combination of the three different functions or cytokine combinations for each individual in order to confirm the segregation of groups obtained by the combinations derived by MDA. As can be seen, oligosymptomatic individuals produced both Th1 and Th2 cytokines, with IFN- $\gamma$ production being observed only in this clinical form. Therefore, MDA was able to distinguish between the subclinical and acute forms of VL based on the observation of the production of cytokines which, combined, determined differentiated cytokine profiles. The detection of cytokines characterizing only a Th2 profile in the acute form should be emphasized (function $1=$ IL-4, IL-10 and TNF- $\alpha$ ).

In view of the variability in clinical manifestations and laboratory alterations observed for individuals with the subclinical form (Table 3), we correlated these parameters with cytokine production which also suffered variations in the levels detected. However, no statistically significant differences were observed. 

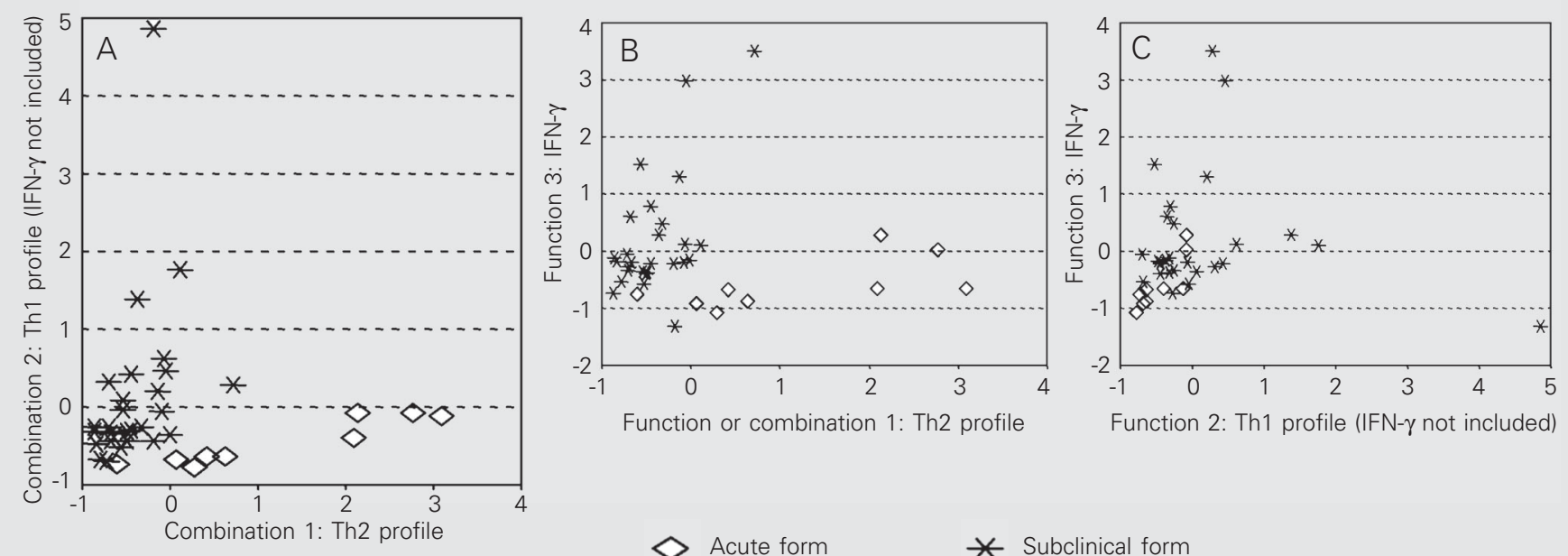

Figure 3. A, Distribution of the individuals according to the clinical form of visceral leishmaniasis based on the cytokine profile determined by multiple discriminant analysis (function or combination). In panels A, B and C, the subjects are segregated into 2 clinical subgroups according to the different cytokine profile.

Table 3. Clinical and laboratory findings obtained for 27 children classified as oligosymptomatic and their correlation with serum cytokine levels.

\begin{tabular}{|c|c|c|c|c|c|c|c|c|c|c|c|c|c|c|}
\hline \multirow{2}{*}{$\begin{array}{l}\text { Patient } \\
\text { number }\end{array}$} & \multirow{2}{*}{$\begin{array}{c}\text { Age } \\
\text { (months) }\end{array}$} & \multicolumn{4}{|c|}{ Symptoms/signs } & \multicolumn{4}{|c|}{ Laboratory findings } & \multicolumn{5}{|c|}{ Cytokine level (pg/ml) } \\
\hline & & Pallor & Diarrhea & $\begin{array}{l}\text { Hepato- } \\
\text { megaly }\end{array}$ & $\begin{array}{l}\text { Spleno- } \\
\text { megaly }\end{array}$ & $\begin{array}{l}\text { Lympho- } \\
\text { cytosis }\end{array}$ & $\begin{array}{l}\text { Hyperglo- } \\
\text { bulinemia }\end{array}$ & $\uparrow B S R$ & $\begin{array}{c}\text { Bone marrow } \\
\text { aspirate }\end{array}$ & IL-2 & IL-10 & IL-12 & IFN- $\gamma$ & TNF- $\alpha$ \\
\hline 1 & 13 & No & No & Yes & No & No & Yes & Yes & NP & 15.6 & 6.6 & 0 & 0 & 5.2 \\
\hline 2 & 10 & No & Yes & No & No & Yes & Yes & Yes & NP & 0 & 10.7 & 0 & 0 & 15.2 \\
\hline 3 & 8 & Yes & No & No & No & Yes & Yes & Yes & NP & 0 & 7.6 & 116.0 & 0 & 19.3 \\
\hline 4 & 14 & No & No & Yes & No & Yes & No & Yes & NP & 0 & 100.7 & 11.1 & 0 & 16.6 \\
\hline 5 & 27 & No & No & Yes & No & No & No & Yes & Negative & 9.1 & 6.2 & 0 & 111.1 & 16.3 \\
\hline 6 & 28 & No & No & No & Yes & No & No & Yes & $\tilde{N} P$ & 0 & 24.6 & 9.8 & 0 & 29.7 \\
\hline 7 & 25 & No & Yes & No & Yes & Yes & No & Yes & Positive & 7 & 6.8 & 5.1 & 8.4 & 43.9 \\
\hline 8 & 13 & No & No & Yes & No & No & Yes & Yes & $\tilde{N} P$ & 6.5 & 11.3 & 47.0 & 0 & 5.0 \\
\hline 9 & 37 & No & No & Yes & No & No & Yes & No & $\tilde{N} P$ & 0 & 35.9 & 70.3 & 150.6 & 12.9 \\
\hline 10 & 21 & No & Yes & Yes & No & Yes & Yes & Yes & Negative & 0 & 0 & 12.7 & 13.3 & 29.1 \\
\hline 11 & 48 & No & No & No & Yes & No & Yes & No & Negative & 0 & 60.9 & 68.9 & 0 & 22.5 \\
\hline 12 & 19 & Yes & No & Yes & Yes & No & No & Yes & Positive & 8.9 & 5.8 & 9.6 & 11.7 & 18.5 \\
\hline 13 & 21 & Yes & No & Yes & No & Yes & Yes & Yes & Negative & 0 & 12.9 & 0 & 24.1 & 15.4 \\
\hline 14 & 32 & Yes & Yes & No & No & No & Yes & Yes & Negative & 10.3 & 0 & 7.5 & 26.4 & 5.4 \\
\hline 15 & 31 & Yes & Yes & No & No & Yes & Yes & Yes & Negative & 130.5 & 0 & 105.3 & 0 & 8.5 \\
\hline 16 & 14 & Yes & No & No & No & Yes & Yes & Yes & Negative & 0 & 43.5 & 26.7 & 0 & 50.9 \\
\hline 17 & 16 & Yes & No & No & No & No & No & Yes & Positive & 7.7 & 25.8 & 48.7 & 0 & 16.8 \\
\hline 18 & 14 & No & Yes & No & No & No & Yes & Yes & Positive & 0 & 80.9 & 52.1 & 173.3 & 58.0 \\
\hline 19 & 13 & No & No & No & Yes & Yes & Yes & No & Negative & 0 & 91.1 & 9.5 & 0 & 5.7 \\
\hline 20 & 20 & Yes & No & Yes & No & Yes & Yes & Yes & Positive & 13.5 & 11.5 & 11.5 & 0 & 32.4 \\
\hline 21 & 31 & Yes & Yes & No & No & Yes & Yes & Yes & Negative & 8.1 & 14.0 & 10.0 & 59.0 & 5.1 \\
\hline 22 & 37 & Yes & No & No & No & Yes & Yes & Yes & Negative & 0 & 41.0 & 24.0 & 54.4 & 4.7 \\
\hline 23 & 29 & No & No & Yes & No & Yes & No & Yes & Positive & 5.0 & 65.1 & 16.2 & 41.1 & 1.3 \\
\hline 24 & 46 & No & Yes & Yes & No & Yes & Yes & Yes & Positive & 5.2 & 11.1 & 32.0 & 0 & 27.0 \\
\hline 25 & 26 & No & No & Yes & Yes & Yes & No & Yes & Negative & 5.5 & 6.9 & 5.6 & 20.3 & 5.4 \\
\hline 26 & 15 & Yes & No & Yes & Yes & Yes & Yes & Yes & Positive & 0 & 56.6 & 50.9 & 68.7 & 11.5 \\
\hline 27 & 20 & No & No & Yes & Yes & Yes & No & Yes & Positive & 17.4 & 27.3 & 102.7 & 0 & 51.9 \\
\hline
\end{tabular}

$\mathrm{BSR}=$ blood sedimentation rate; NP = not performed (due to problems with material collection). 


\section{Discussion}

The factors determining the development of a clinically manifested form of VL (acute or classic form) have not yet been completely identified. The deficient production of IFN- $\gamma$ after exposure to Leishmania antigen is one of the commonly reported factors and is associated with an increase in CD4+ Th cells expressing a Th2 cytokine profile (susceptibility), with the production of IL-4, IL-10 and TNF- $\alpha$ but not of IL- 2 or IL-12 $(8,15-18)$. The variation in the detectable levels of IL-10 and TNF- $\alpha$ observed in the present study for the acute form has also been described by others (19-21). Thus, the Th2 profile with oscillating cytokine levels detected in the present study for cases characterized as the acute form of the disease is in agreement with data reported in the literature $(22,23)$.

With respect to the subclinical form, the comparison with literature data regarding the detection of cytokines is difficult since such findings refer to the determination of cytokine concentrations in the supernatant of lymphocyte cultures after stimulation with Leishmania antigen - a fact that by itself justifies the differences observed here, in addition to the different technical conditions.

Bacellar et al. (7) observed the production of IFN- $\gamma$ in the culture supernatant of $100 \%$ of subclinical cases with spontaneous cure (ranging from 3 to $321 \mathrm{U} / \mathrm{ml}$ ), while Barral-Netto et al. (6) did not detect TNF- $\alpha$ in the culture supernatant of patients with this clinical form. It should be noted that the data reported by these investigators refer to cases clinically described by Badaró et al. (24), with the blood samples being collected before the occurrence of clinical manifestations.

Analysis of the levels of IL-2, IL-4, IL-10 or IL-12 in individuals with the oligosymptomatic form has not been previously performed by other investigators.

In the present study, variability in the cytokine levels and profiles was observed for the oligosymptomatic form, with both resistance (IL-2, IL-12 and IFN- $\gamma$ ) and susceptibility (IL-10) profiles being detected. Holaday et al. (25) have suggested that low levels of IFN- $\gamma$ in response to Leishmania antigen in children with subclinical infection correspond to an intermediate position between disease and protective immunity.

Since Leishmania is an obligate intracellular parasite and macrophages are the cells of choice, it is important to determine the profile of more than one cytokine in order to explain the discrete and self-limited symptoms observed in individuals with the subclinical form of the disease.

Based on immunological findings and data regarding VL disease (production of susceptibility profile cytokines, Th2) and infection (resistance profile, Th1), one can infer that in the oligosymptomatic or subclinical form the production of Th1 cytokines (IL-2, IL-12 and IFN- $\gamma$ ) influences the self-limited evolution of the clinical signs and symptoms, culminating in their spontaneous resolution, as reported in studies since 1906 (13,16,25-27). Comparative analyses have been impaired over the years by the use of different terminologies, with some authors inadequately using the term "infection" as a synonym for "asymptomatic" or "subclinical" (13).

IL-4 plays an important role in the progression to disease and is also involved in the down-regulation of IFN- $\gamma$, suggesting that its non-detection has a positive effect on the evolution from the subclinical form to spontaneous resolution $(8,28)$.

The clinical manifestations and laboratory alterations observed in the present study for individuals with the subclinical form were related to the detection of susceptibility profile cytokines (Th2), considering that TNF- $\alpha$ is the main factor involved in systemic alterations and, consequently, in the symptomatology observed in VL (29-31). IL-10 plays a fundamental role in this process since it 
seems to be responsible for the inhibition of the synthesis of the main macrophage-stimulating cytokine involved in the defense against Leishmania, i.e., IFN- $\gamma(8,32)$.

The behavior of TNF- $\alpha$ depends on the production of cytokines such as IL-4 and $\operatorname{IFN}-\gamma(5,33)$ and, although also present in individuals who are only infected, it is present at higher levels in individuals with the disease. Therefore, we may assume that the significantly lower levels of IL-10 and TNF$\alpha$ observed in the present study for oligosymptomatic individuals were probably due to the production of Th1 cytokines and contributed to the discrete clinical manifestations.

The mixed cytokine profile observed for individuals with the subclinical form agrees with findings in the literature showing the existence of different $\mathrm{T}$ cell subgroups pro- ducing only IFN- $\gamma$ or IL-4 and IFN- $\gamma$ simultaneously (34). The cited authors emphasized the importance of these IFN- $\gamma$ and IL-10 secretory $\mathrm{T}$ cells in the maintenance of the balance between the Th1 and Th2 profile.

After the observation that oligosymptomatic or subclinical individuals show a welldifferentiated clinical behavior compared to individuals with the clinically manifested form of VL (13), the results of the present study indicate that the production of susceptibility and resistance cytokines plays an important role in the outcome of infection in oligosymptomatic patients.

\section{Acknowledgments}

Special thanks are due to Dr. Márcia Dalastra Laurenti.

\section{References}

1. World Health Organization (1991). Control of Leishmaniasis. Report of a WHO Expert Committee. Technical Report Series, Geneva, Switzerland.

2. Ministério da Saúde, Brasil (1996). Controle, Diagnóstico e Tratamento de Leishmaniose Visceral (Calazar) - Normas Técnicas. Fundação Nacional de Saúde, Brasília, DF, Brazil.

3. Bittencourt A \& Barral-Netto M (1995). Leishmaniasis. In: Doeer W (Editor), Tropical Pathology. Springer-Verlag, Berlin, Germany, 597651.

4. Holaday B (2000). Role of CD8+ T cells in endogenous interleukin10 secretion associated with visceral leishmaniasis. Memórias do Instituto Oswaldo Cruz, 95: 217-220.

5. Liew F, Millott S, Parkinson C, Palmer R \& Mancada S (1990). Macrophage killing of Leishmania parasites in vivo is mediated by nitric oxide from L-arginine. Journal of Immunology, 144: 47944797.

6. Barral-Netto M, Badaró B \& Barral A (1991). Tumor necrosis factor (cachectin) in human visceral leishmaniasis. Journal of Infectious Diseases, 163: 853-857.

7. Bacellar O, Barral-Netto M, Badaró R \& Carvalho E (1991). Gamma interferon production by lymphocytes from children infected with $L$. chagasi. Brazilian Journal of Medical and Biological Research, 24: 791-795.

8. Carvalho E, Bacellar O, Brownell C, Regis I, Coffman R \& Reed S (1994). Restoration of IFN- $\gamma$ production and lymphocyte proliferation in visceral leishmaniasis. Journal of Immunology, 152: 5949-5956.

9. Carvalho E, Almeida R \& Jesus A (1995). Imunidade e infecção. Medicina, 28: 253-283.

10. Ghalib H, Wittle J \& Kubin M (1995). IL-12 enhances Th1-type responses in human Leishmania donovani infections. Journal of
Immunology, 154: 4623-4629.

11. Sang D, Ouma J \& John C (1999). Increased levels of soluble interleukin-4 receptor in the sera of patients with visceral leishmaniasis. Journal of Infectious Diseases, 179: 743-746.

12. Carvalho E, Barral A \& Pedral-Sampaio D (1992). Immunological markers of clinical evolution in children recently infected with Leishmania donovani chagasi. Journal of Infectious Diseases, 165: 535540.

13. Gama M (2001). Perfil clínico e laboratorial da forma oligossintomática da leishmaniose visceral americana. Doctoral thesis, Departamento de Patologia, Faculdade de Medicina, Universidade de São Paulo, São Paulo, SP, Brazil.

14. Caldas A, Silva D, Pereira C \& Costa JML (2001). Infecção por Leishmania (Leishmania) chagasi em crianças de uma área endêmica de leishmaniose visceral americana, na Ilha de São Luís, Maranhão, Brasil. Revista da Sociedade Brasileira de Medicina Tropical, 34 445-451.

15. Badaró R (1988). Progressos nas pesquisas de leishmaniose visceral na área de Jacobina, Bahia 1934-1989. Revista da Sociedade Brasileira de Medicina Tropical, 21: 159-164.

16. D'Oliveira Jr A, Costa S, Barbosa A, Orge M \& Carvalho E (1997). Asymptomatic Leishmania chagasi infection in relatives and neighbors of patients with visceral leishmaniasis. Memórias do Instituto Oswaldo Cruz, 92: 15-20.

17. Mattner F, Padova K \& Alber G (1997). Interleukin-12 is indispensable for protective immunity against Leishmania major. Infection and Immunity, 65: 4378-4383.

18. Bogdan C \& Rollinghoff M (1998). The immune response to Leishmania: mechanisms of parasite control and evasion. International Journal for Parasitology, 28: 121-134. 
19. Salomão R, Castelo Filho A, Medeiros I \& Sicolo M (1996). Plasma levels of tumor necrosis factor- $\alpha$ in patients with visceral leishmaniasis: association with activity of the disease and clinical remission following antimonial therapy. Revista do Instituto de Medicina Tropical de São Paulo, 38: 113-118.

20. Medeiros I (1997). Avaliação prospectiva dos níveis de gama interferon, interleucina-10 e fator de necrose tumoral- $\alpha$ antes, durante e ao final da terapêutica da leishmaniose visceral. Doctoral thesis, Escola Paulista de Medicina, São Paulo, SP, Brazil.

21. Babaloo Z, Kaye P \& Eslami M (2001). Interleukin-13 in Iranian patients with visceral leishmaniasis: relationship to other Th2 and Th1 cytokines. Transactions of the Royal Society of Tropical Medicine and Hygiene, 95: 85-88.

22. Zwingenberger K, Harms G, Pedrosa C, Omena S, Sandkamp B \& Neifer S (1990). Determinants of the immune response in visceral leishmaniasis: evidence for predominance of endogenous interleukin-4 over interferon- $\gamma$ production. Clinical Immunology and Immunopathology, 57: 242-249.

23. Sundar S, Reed S, Sharma S, Mehrotra A \& Murray H (1997). Circulating T helper 1 (Th1) cell- and Th2 cell-associated cytokines in Indian patients with visceral leishmaniasis. American Journal of Tropical Medicine and Hygiene, 56: 522-525.

24. Badaró R, Jones $T$ \& Carvalho $E$ (1986). New perspectives on a subclinical form of visceral leishmaniasis. Journal of Infectious Diseases, 154: 1003-1011.

25. Holaday B, Pompeu M, Evans T et al. (1993). Correlates of Leishmania-specific immunity in the clinical spectrum of infection with Leishmania chagasi. Journal of Infectious Diseases, 167: 411-417.

26. Leishman W (1976). Handbuch der Tropenkrankheiten. 2nd edn. Leipzig 1906 apud Pampiglione S, Manson-Bahr P, Giungi F, Giunti
G, Parenti A \& Troti G. Studies on Mediterranean leishmaniasis II. Asymptomatic cases of visceral leishmaniasis. Transactions of the Royal Society of Tropical Medicine and Hygiene, 68: 349-358.

27. Guerra M, Furtado T, Barros G, Sessa P \& Daher V (1985). Infecção subclínica na leishmaniose tegumentar. Anais Brasileiros de Dermatologia, 60: 365-369.

28. Uyemura K, Pirmez C, Sieling P, Kiene K, Paes-Oliveira M \& Modlin $R$ (1993). CD4+ type 1 and CD8+ type $2 \mathrm{~T}$ cell subsets in human leishmaniasis have distinct $\mathrm{T}$ cell receptor repertoires. Journal of Immunology, 151: 7095-7104.

29. Oppenheim J, Ruscetti F \& Faltynek C (1991). Citocinas. In: Stiles D \& Abba T (Editors), Imunologia Básica. Revinter, Rio de Janeiro, RJ, Brazil, 61-76.

30. Stevens D (1995). Cytokines: an updated compendium. Current Opinion in Infectious Diseases, 8: 175-180.

31. Janeway C \& Travers P (1997). Imunobiologia: O Sistema Imunológico na Saúde e na Doença. Artes Médicas, Porto Alegre, RS, Brazil.

32. Ghalib H, Piuvezam M, Skeiky Y, Siddig M, Hashim FA, el-Hassan AM, Russo DM \& Reed SG (1993). Interleukin 10 production correlates with pathology in human Leishmania donovani infection. Journal of Clinical Investigation, 92: 324-329.

33. Raziuddin S, Abdalla R, El-Awad E \& Al-Janadi M (1994). Immunoregulatory and proinflammatory cytokine production in visceral and cutaneous leishmaniasis. Journal of Infectious Diseases, 170: 1037 1040 .

34. Kemp K, Kemp M, Kharazmi A, Ismail A, Kurtzhals JA, Hviid L \& Theander TG (1999). Leishmania-specific T cells expressing interferon-gamma (IFN-gamma) and IL-10 upon activation are expanded in individuals cured of visceral leishmaniasis. Clinical and Experimental Immunology, 116: 500-504. 